\title{
Use of Scratch as ICT Educational Tool in Health
}

\author{
Theodora ARGYRI ${ }^{\mathrm{a}, 1}$, Emmanouil ZOULIAS ${ }^{\mathrm{a}}$, Joseph LIASKOS ${ }^{\mathrm{a}}$ \\ and John MANTAS ${ }^{a}$ \\ ${ }^{a}$ Health Informatics Laboratory, Faculty of Nursing, National and Kapodistrian \\ University of Athens, Athens, Greece
}

\begin{abstract}
Education adds knowledge, experience, and skills to the human personality, from childhood to old age. This paper focuses on adult education, presenting the difficulties, techniques and results that have been demonstrated to produce educational training program, including material using Scratch. Referring to the planned education from the school, university or any other institution, the educators have a duty to share their knowledge with the students, to show them the way of knowledge, learning, and exploration. They are constantly looking for new training techniques and methods that will attract anyone interested. An important role in this continuous effort is called to play the technology, which nowadays evolves. This paper addresses some of the advantages and disadvantages of technology in health training, how technology can be used and how it can be combined with training. In addition, important issues for health training are mentioned. The training program, the target group to which it is addressed, the means to be used and the objectives are presented in detail. Finally, technological training programs were created, which will enrich the specially designed training program, for which the methodology used, and their purpose will be analyzed.
\end{abstract}

Keywords. Health training, Health Informatics, Artificial Intelligence, Games

\section{Introduction}

As a pedagogical scientific approach of adult education and training nowadays is «the systematic and organized process of teaching and learning» [1], based on a specially designed program, specific methods, within a certain time frame, educational objectives and with tools that are defined beforehand. [2]. Researchers of the Assessment and Teaching of 21st Century Skills (ATC21S) framework, concluded that 21 st century skills can be grouped into four broad categories: (i) ways of thinking, (ii) ways of working, (iii) tools for working and (iv) skills for living in the world [3]. It has been proven that technology promotes the adult educational and training process [4].

Several studies on health training exploiting Information and Communication Technology (ICT) tools rely either on training patients to comply with prevention and treatment $[5,6,7]$, or on training health professionals to improve quality of care $[6,8]$. Mobile tablet-based educational tools [7] or online interactive educational tools $[5,6,8]$ have been used for the training of health providers. These studies have concluded that

${ }^{1}$ Corresponding Author, Theodora Argyri, Health Informatics Laboratory, Faculty of Nursing, National and Kapodistrian University of Athens, Athens, Greece; E-mail: dora.argyri@gmail.com. 
the use of ICT tools enriches learners' knowledge and promotes the correct response to health-related events $[6,8]$.

This work presents the exploitation of Scratch as an ICT tool to produce interactive educational/training material for the training needs of potential health professionals (e.g., student nurses, student physicians), as well as non-professionals, like patients, in the introduction of the cardiovascular system anatomy. Scratch is a graphical dynamic programming tool for trainers and teachers to produce interactive educational/training material [9]. According to the literature search in major databases, no previous application appears in health training.

\section{Methods}

During the design phase of this study the researchers predefined the scenarios, texts and images that would be embodied in the produced training material. The first scenario designed, assuming that a potential user selects a region of interest of the heart's graphical representation, and the corresponding information is displayed. The second one presents an introduction of the parts of the heart, and it is initiated when the user presses the corresponding button onto the heart's graphical representation. The third scenario illustrates the automatic translation of the training material presented made by Scratch in several languages. During the design phase, the online version of Scratch was used (https://scratch.mit.edu/). The development of the training materials performed by a registered nurse, the main researcher of this work, having no programming experience but high management ability of ICT.

The tests performed were limited, initially within the research team members, and then by a small number of 15 volunteers, consisted of health experts' trainers, health expert trainees, public. These participants who tested, also evaluated the educational/training tool and material, and they were interviewed through unstructured interviews. The interviews included open questions regarding the functionality, content, error detection, and aesthetics of the tool. However, answers were not recorded systematically.

\section{Results}

For the teaching needs of cardiac anatomy, three different educational games were created, as interactive or animation teaching/ learning tools, using Scratch. The first one (Figure 1) is an interactive tool that presents the graphical representation of heart, where the user may select a specific point of the cardiac graphical representation, which corresponds to a specific part of human heart that interests him, and the corresponding information is automatically displayed. This Scratch game created, is available online on the link https://scratch.mit.edu/projects/437563118. 

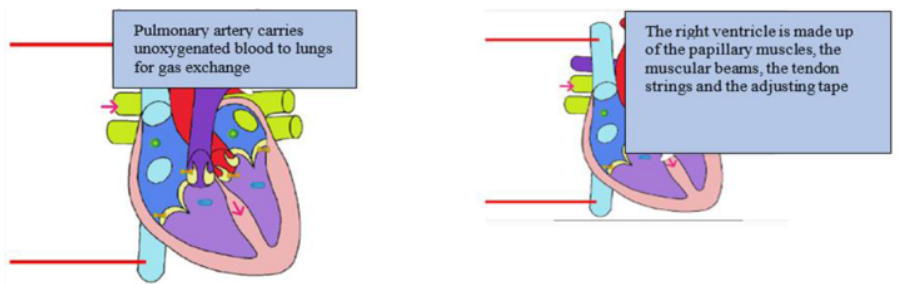

Figure 1. Heart anatomy interactive learning tool.

The second one, is an animation tool that further enhances the basic heart anatomy training by naming and listing the parts of human heart in its graphical representation (Figure 2). It is available on the link https://scratch.mit.edu/projects/437599456.
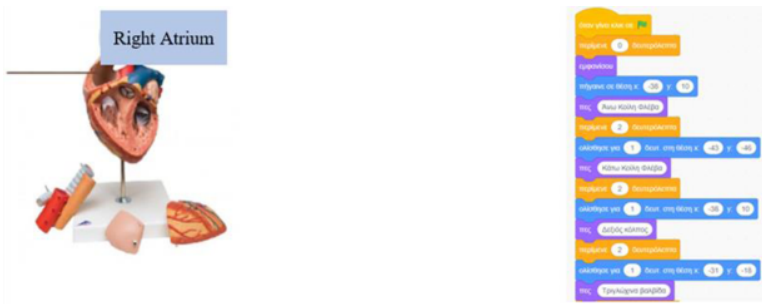

Figure 2. Heart anatomy animation tool, and its Scratch code.

The third one automatically translates the training material to several languages available, adapting the course to various languages speakers' trainees (Figure 3). It is available on the link https://scratch.mit.edu/projects/522423819.
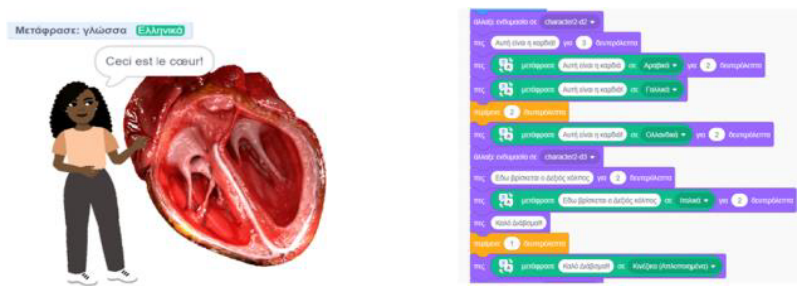

Figure 3. Animation tool translating the training material in several languages, and its Scratch code

The results of the evaluation of the material showed that in general it is an easy to use and understandable tool. Few people encountered difficulties in using it, which were overcome by explaining how the tool works.

\section{Discussion}

Our study is expected to assist interactive training of health professionals and students to provide better quality of care [6,8], and train patients to better understand aspects of their health or still comply to their treatment $[5,6,7]$. There are studies that prepare presentation of health issues targeting students [9]. In this work the training material created additionally offers interactive, animated, and multilingual material. Several difficulties have been encountered for the design and creation of the training tool, which teaches the «Anatomy of the Heart». As far as the first game/ tool created is concerned, one difficulty was the integration of interactivity. Another one was to provide suitable concise, simple, and easily understandable training material, which provides all the 
necessary information of heart anatomy. On the other hand, the other two animated games/ tools were created easier and faster than the first one.

The main limitation of our study is the small number of trainees evaluated the training tools and material, and the fact that their responses were not systematically recorded.

\section{Conclusions}

In this study, educational/ training material was created, related to basic anatomy of the heart, for the training needs of both health and non-health professionals. Three educational material, as interactive or animated educational tools were created using Scratch as ICT tool. The introduction of ICT gaming tools like Scratch in health training may provide an alternative interactive educational approach, enhance the learning experience, and motivate the trainees. The use of Scratch for creating educational material requires no programming skills, and its learning curve has been proved low. The type of educational material presented in this study, is suitable for distance learning, for people with special needs, and for trainees who work, by considering their available time and pace; moreover, it facilitates home training and learning in movement restrictions, like those imposed during COVID-19 pandemic [10].

In our next steps, we plan to evaluate the training tools created with a more structured and systematical way; moreover, to create training tools and material in health, suitable for the learning needs of disabled people. Such example would be the design of a training tool, which exploits a computer-based built-in camera for detecting the facial movement of the trainee, in order to automatically display the learning information.

\section{References}

[1] Xochelis P, Introduction in Pedagogical: Funtamental problems in Pedagogical Science, Thessaloniki: Kiriakidis (In Greek). 2010.

[2] Pedagogical psychological encyclopedia - Dictionary. Athens: Greek Letters; 1989:1-601.

[3] Binkley M, Erstad O, Herman J, Raizen S, Ripley M, Miller-Ricci M, and Rumble M. Defining TwentyFirst Century Skills Book Assessment and Teaching of 21st Century, 2012 Editors: Patrick Griffin Barry McGaw Esther Care, Springer 10.1007/978-94-007-2324-5.

[4] Roger M. The purposes of education. Athens: Metaichmio; 2003:1-368.

[5] Silva Junior GB, Oliveira JGR, Araújo EMR, Albuquerque ACRMM, Mota FAX, Freitas Filho RA, Vasconcelos Filho JE, Rodrigues MAF. Renal Health: Providing Information and Technological Tools to Empower Patients to Live Better with Kidney Disease. Stud Health Technol In-form. 2021 May 27;281:674-678.

[6] Hendricks M, Varathan O, Cassim F, Kidd M, Moodley K. Impact of implementing an online interactive educational tool for future HIV cure research in an HIV clinic waiting room in Cape Town, South Africa. AIDS Care. 2020 Aug;32(8):965-969.

[7] Bowman C, Lunyera J, Alkon A, Boulware LE, St Clair Russell J, Riley J, Fink JC, Diamantidis CA Patient Safety Educational Tool for Patients With Chronic Kidney Disease: Development and Usability Study. JMIR Form Res. 2020 May 28;4(5):e16137.

[8] Choueiry J, Reszel J, Hamid JS, Wilding J, Martelli B, Harrison D. Development and Pilot Evaluation of an Educational Tool for the FLACC Pain Scale. Pain Manag Nurs. 2020 Dec;21(6):523-529.

[9] Ramos VP. ICT in the curriculum using scratch with students of the alternative curriculum. 2015 International Symposium on Computers in Education (SIIE); 2015;9-72, doi: 10.1109/SIIE.2015.7451650.

[10] Iatronet. Home education: The first learning impulse in the child [Internet]. 2014 [cited 9 January 2021]. Available at: https:/www.iatronet.gr/ygeia/paidiatriki/article/25755/ekpaidefsi-apo-to-spiti-i-prwti-mathisiaki-wthisi-sto-paidi.html. 